\title{
FREQUENCY OF SEROPOSITIVITY \& OCCUPATIONAL RISKS OF HBV INFECTION IN A TEACHING HOSPITAL IN BANGLADESH
}

\author{
DEVENDRA NATH SARKAR ${ }^{1}$, MD.ISMAIL HOSSAIN ${ }^{2}$, A.K.M SHAHEDUZZAMAN ${ }^{3}$, MAINUDDININ AHMED $^{4}$, \\ ROBED AMIN 5
}

\begin{abstract}
Background: Hepatitis remains one of the major public health problems of the developing world. HBV infection is a potentially life threatening condition as many of the affected individuals progress to chronic hepatitis, cirrhosis and hepatocellular carcinoma (HCC).

Aims and objectives: This study aimed to determine the frequency of different seropositive tests \& occupational risks of HBV infected patient admitted in Rangpur Medical College hospital and thereby advice for appropriate measures including referral for selected cases.

Methods: Data of all patients aged 12 years and above diagnosed as HBV infection in the medical wards between January 2011 to June 2012 were retrieved from their case records and analyzed.

Results: Among the 80 patients 8 (10\%) had the history of vaccination but no history of giving booster dose nor checking antibody titre, 72 (90\%) had no history of vaccination. Regarding risk factor for HBV infection 58 (male=49, female $=09$ ) had the history of sexual exposure, 08 (male=05, female=03) had the history of transfusion of blood or blood products, 05 (male=04, female=01) had the history of injury with contaminated instrument (Needle stick / Blade / Lancet/Others), 04 (male=04, female $=00$ ) had the history of professional blood donation, 03 (male=03, female=00) had the history of infusion and 02 (male $=01$, female $=01$ ) had history of major/ minor surgery. Regarding seroprevalence among 80 patients 71 (89\%) had seropositive of HBsAg (ELISA) and remaining were seronegetive but positive of Anti HBc, 54 (68\%) had seropositive of Anti HBc. Among sixty six male patient twenty four (36\%) are businessman, twenty one (33\%) are service holder, eleven are day labourer, six (9\%) are student, and four (5\%) are farmer. In female patient eight (57\%) out of fourteen are housewife, three (22\%) are day labourer, two (14\%) are service holder and one (7\%) patient is student.

Conclusion: Hepatitis Binfection remains in Bangladesh an important disease with substantial mortality and morbidity that primarily affects unvaccinated or inadequately vaccinated individuals. Business man in case of male \& house wife in case of female are more vulnerable among the risk group. This must be brought in to attention of institutions responsible for planning health care prog ra m mes. [* Internal error: Invalid file format. | In-line. WMF*]
\end{abstract}

\section{Introduction}

Hepatitis B virus infection is an important public health problem with significant morbidity and mortality. It is the 10th leading cause of death worldwide, and results in 500,000 to 1.2 million deaths per year caused by chronic hepatitis, cirrhosis and hepatocellular carcinoma (HCC). HCC accounts for 320000 deaths per year ${ }^{(1)}$. Recombinant hepatitis $B$ vaccination for the prevention of hepatitis $B$ virus infection is in practice in different parts of the world since its availability in 1986. Government of Bangladesh has also included hepatitis B vaccine in EPI schedule since 2005.

In Asia there are about 93 million HBsAg-positive subjects, of whom about 20 million have chronic hepatitis B infection. Around half-a-million patients die from hepatitis B-related liver carcinoma and endstage cirrhosis each year ${ }^{(2)}$. There is no ideal and specific cure for HBV infection. The economic burden of HBV infection is substantial because of high morbidity and mortality associated with endstage

1. Associate Professor, Department of Medicine, Rangpur Medical College \& Hospital, Rangpur.

2. Registrar, Department of Medicine, Rangpur Medical College \& Hospital, Rangpur.

3. Assistant Professor, Department of Medicine, Rangpur Medical College \& Hospital, Rangpur.

4. Indoor Medical Officer, Department of Medicine, Rangpur Medical College \& Hospital, Rangpur.

5. Associate Professor, Department of Medicine, Dhaka Medical College \& Hospital, Dhaka.

Bangladesh J Medicine 2013; 24 : 20-24 
liver disease, cirrhosis and hepatocellular carcinoma (HCC) ${ }^{(3)}$. The modes of transmission of $\mathrm{HBV}$ vary between different regional, gender, and age groups (3).The sources of infection of hepatitis B are mainly chronic hepatitis $B$ patients and asymptomatic viral carriers. Three major routes spread HBV: parenteral, horizontal, and sexual transmission (4).In developing countries, the main routes of transmission are: neonatal with HBV carrier mother infecting her infant usually during birth or soon after birth following close contact, transfer of HBV via cuts, sexual transmission, transfusion of infected blood or blood products, needle stick injury, contamination of eye, re-use of $\mathrm{HBV}$ contaminated needles, syringes, lancets and instruments including those used in tribal ceremonies, possibly blood sucking insects and bed bugs (5). Parenteral transmission is believed to account for $35-50 \%$ of carriers although horizontal transmission is also important, particularly within families (6). Adults infected with HBV usually acquire acute hepatitis B and recover, but $5-10 \%$ develops the chronic carrier state. Government, despite of the availability of safe and effective $\mathrm{HBV}$ vaccines for over 20 years, have failed to target risk group sufficiently to control hepatitis B transmission in the current population. HBV transmission has become an important mode of infection in adults, mainly because of difficulties in risk identification and in program implementation. Therefore, we conducted this study to determine the Seroprevalence \& Occupational risks of HBV infection in an adult population admitted in RpMC\&H.

Despite the availability of an effective vaccine, Hepa-titis B virus (HBV) infection still remains an important health problem. Undoubtedly, finding the key routes of hepatitis transmission from the point of prevention in every country, specifically in endemic regions, is of high priority. Such efforts are especially important given that many infected patients with hepatitis are asymptomatic 7,8 . HBV accounts for $35 \%$ acute viral hepatitis, $40.5 \%$ chronic liver disease, $36.5 \%$ hepatocellular carcinoma and $29.1 \%$ cases of post transfusion hepatitis. Blood donors are not routinely screened for HBsAg except in a few selected centers. Twenty-nine percent of professional blood donors and $2.4 \%$ of voluntary blood donors are $\mathrm{HBsAg}$ carriers. HBs Ag is positive in $7.5 \%$ of healthy adult jobseekers ${ }^{7}, 8$. In conclusion, $\mathrm{HBV}$ is the main aetiological factor for chronic liver disease in Bangladesh.

\section{Materials and Methods}

All cases of hepatitis B virus infection in patients aged 12 years and above from January 2011 to July 2012, were included in this 18-month cross sectional study. Patients getting admission in indoor of Medicine and Gastroenterology units of Rangpur Medical College Hospital over the study period and diagnosed as having Hepatitis B virus infection were selected for the study. Diagnosis was established by clinical feature, physical examination and subsequent laboratory and imaging studies. Selection criteria for the patients consists of: (1) Physicians made clinical diagnosis of hepatitis (2) Age of 12 years or above and both sexes.

80 respondents and their reliable attendant were interviewed by structured questionnaire. Detailed history and relevant laboratory investigations were carried out and recorded on the fixed proforma. The HbsAg with ELISA methods was done in all cases. Those who are positive were also investigated with $\mathrm{HbEAg}$ if activity is suspected. Those who were HbsAg negative but suspicion of hepatitis B were high, AntiHbc were done and if they are positive included in the study. When the HbsAg and Total Anti Hbc were negative they were excluded from the study and not analyzed.

\section{Statistical Analysis}

Data was analyzed using SPSS 16 statistical package (9). A descriptive analysis was done on all variables to obtain a frequency distribution. The mean \pm SD and ranges were calculated for quantitative variables. Continuous variables were compared by the Student $t$ test. Proportions were analyzed with the chi-square test or 2-tailed Fisher's exact test as appropriate. A $P$ value of 0.05 or less was considered statistically significant.

\section{Results}

A total of 80 cases of hepatitis B virus infected patient were included in the present study. All were analyzed and presented in graph and tabulated form.

\section{Patient Characteristics:}

During the study period, 80 patients had been included: The mean age of patients in our study was $29.68 \pm$ 10.53 (mean $\pm \mathrm{SD}$ ) years with a range of 12 to 58 years. The maximum number of patients $(\mathrm{N}=31 ; 38 \%)$ belonged to the age group of 21-30 years. The age distribution (table I) of patients at the time of data collection were as follows; 10 patients(13\%) from 11 to 20 years, 31 patients (38\%) from 21 to 30 years, 24 patients(30\%) from 31 to 40 years, 11 patients(14\%) from 41 to 50 years, 4 patients ( $5 \%$ ) from 51 to 60 years.

The gender distribution (table II) were 66 (82\%) males and $14(18 \%)$ females (male: female ratio $=5: 1$ ). 
Table I

Age distribution of the studied subjects

\begin{tabular}{lcc}
\hline Age & $\begin{array}{c}\text { Number of } \\
\text { patients }\end{array}$ & Percentage \\
\hline $11-20$ & 10 & 13 \\
$21-30$ & 31 & 38 \\
$31-40$ & 24 & 30 \\
$41-50$ & 11 & 14 \\
$51-60$ & 4 & 5 \\
\hline
\end{tabular}

Table II Gender distribution of the studied subjects

\begin{tabular}{lcc}
\hline Sex & $\begin{array}{c}\text { Number of } \\
\text { patients }\end{array}$ & Percentage \\
\hline Male & 66 & 82 \\
Female & 14 & 18 \\
\hline
\end{tabular}

$\mathrm{M}: \mathrm{F}$ ratio $=5: 1$

\section{Presenting symptoms and physical signs:}

The main presenting symptoms (Table III) were vomiting $(33 \%, 26 / 80)$, anorexia $(68 \%, 54 / 80)$, abdominal pain $(48 \%, 38 / 80)$, myalgia $(58 \%, 46 / 80)$, arthalgia $(14 \%, 11 / 80)$, headache $(19 \%, 15 / 80)$, dark urine $(23 \%, 18 / 80)$, pale stool $(23 \%, 18 / 80)$

The clinical examination revealed jaundice in 76 $(95 \%)$ patients, anemia in $07(09 \%)$ patients, tattoo mark in $06(08 \%)$ patient, Needle prick mark in 08 $(10 \%)$ patient, scar mark in $07(09 \%)$ patient, fever in $02(03 \%)$ patient, spider naevi in $38(48 \%)$ patients, gynaecomastia in $26(33 \%)$ patients, testicular atrophy in 31 (38\%) patients (TableIII).

Table III

Common clinical presentations of hepatitis B virus infected patient in RpMC\&H

\begin{tabular}{lcc}
\hline Clinical features & $\begin{array}{c}\text { Number of } \\
\text { patients }\end{array}$ & Percentage \\
\hline Anorexia & 54 & 68 \\
Vomiting & 26 & 33 \\
Abdominal pain & 38 & 48 \\
Headache & 15 & 19 \\
Myalgia & 46 & 58 \\
Arthalgia & 11 & 14 \\
Dark urine & 18 & 23 \\
Pale stool & 18 & 23 \\
Anaemia & 07 & 09 \\
Jaundice & 76 & 95 \\
Tattoo mark & 06 & 08 \\
Fever & 02 & 03 \\
Needle prick mark08 & & 10 \\
Scar mark & 07 & 09 \\
Spider naevi & 38 & 48 \\
Gynaecomastia & 26 & 33 \\
Testicular atrophy & 31 & 38 \\
\hline
\end{tabular}

Among the 80 patients $8(10 \%)$ had the history of vaccination but no history of giving booster dose nor checking antibody titre, 72 (90\%) had no history of vaccination (Table IV). Regarding risk factor for $\mathrm{HBV}$ infection 58 (male=49, female=09) had the history of sexual exposure, 08 (male $=05$, female $=03$ ) had the history of transfusion of blood or blood products, 05 (male $=04$, female $=01$ ) had the history of injury with contaminated instrument (Needle stick / Blade / Lancet/Others), 04 (male=04, female=00) had the history of professional blood donation, 03 (male=03, female $=00$ ) had the history of infusion and 02 (male $=01$, female $=01$ ) had history of major $/$ minor surgery (Table V).

Table IV

History of vaccination in patients with HBV infection

\begin{tabular}{lcc}
\hline & Number & $\%$ \\
\hline With vaccination & 08 & 10 \\
Without vaccination & 72 & 90 \\
\hline
\end{tabular}

Table V

Mode of transmission of $H B V$ in patients with $H B V$ infection

\begin{tabular}{lcc}
\hline History & Male & Female \\
\hline $\begin{array}{l}\text { Sexual exposure (N=58) } \\
\text { Transfusion(blood/blood } \\
\text { products)(N=08) }\end{array}$ & 49 & 09 \\
$\begin{array}{l}\text { Contaminated } \\
\text { instrument injury (N=05) }\end{array}$ & 04 & 03 \\
$\begin{array}{l}\text { Professional blood } \\
\text { donar(N=04) }\end{array}$ & 04 & 00 \\
$\begin{array}{l}\text { Infusion (Injection } \\
\text { or saline)(N=03) }\end{array}$ & 03 & 00 \\
$\begin{array}{l}\text { Surgery (major/minor) } \\
(\mathrm{N}=02)\end{array}$ & 01 & 01 \\
\hline
\end{tabular}

Regarding frequency of seropositivity among 80 patients 71 (89\%) had seropositive of HBsAg (ELISA) and remaining were seronegetive but positive of Anti HBc. Fifty four (68\%) had seropositive of Anti HBc.

Figure 1 bar diagram showing relation of occupational history related to Hepatitis B virus infection

\section{Occupational risk:}

Among sixty six male patient twenty four (36\%) are businessman, twenty one (33\%) are service holder, eleven are day labourer, six $(9 \%)$ are student, and four $(5 \%)$ are farmer. In female patient eight $(57 \%)$ out of fourteen are housewife, three $(22 \%)$ are day labourer, two (14\%) are service holder and one $(7 \%)$ patient is student (fig: 1). 

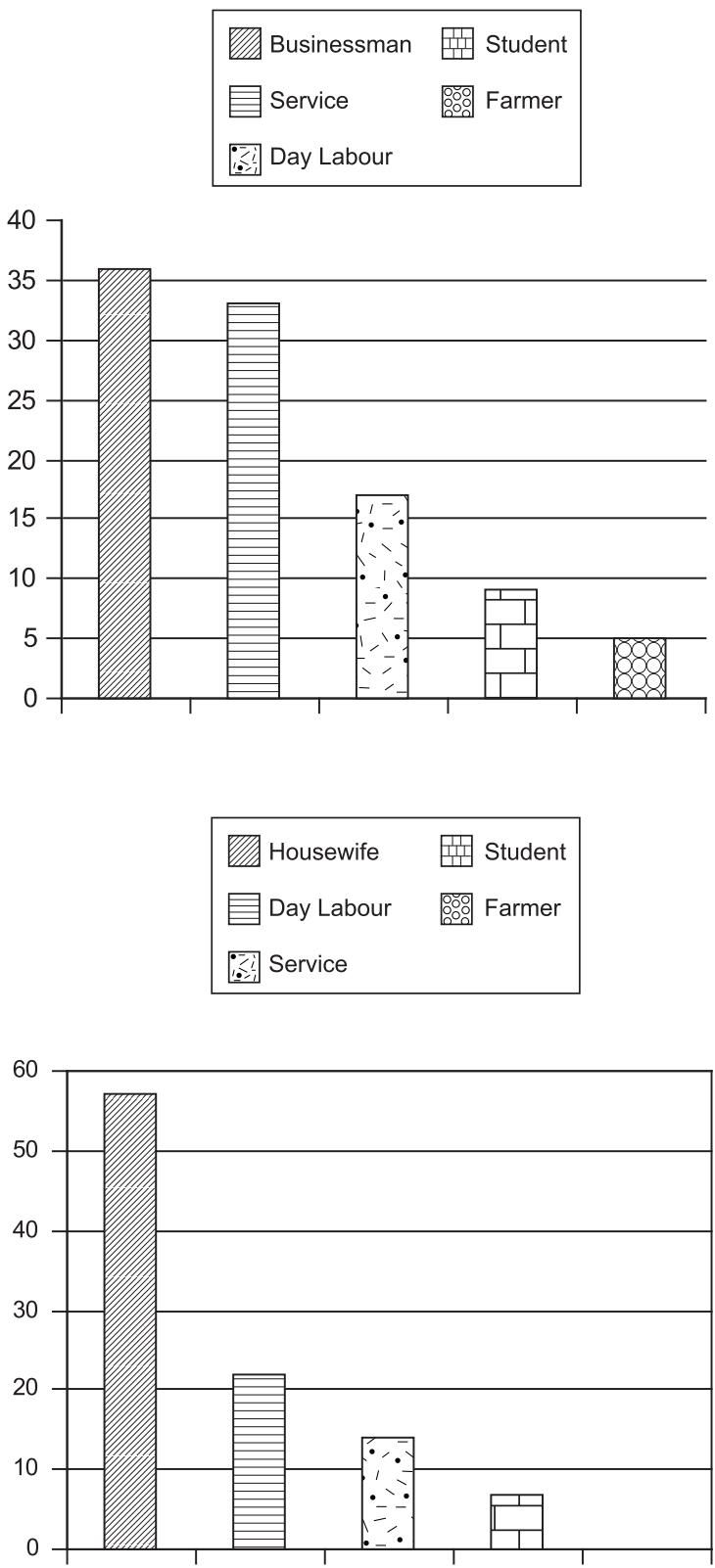

Fig.-1: Bar diagram showing relation of occupational history related to Hepatitis $B$ virus infection

\section{Discussion}

This cross sectional study was undertaken to observe the seroprevalence \& occupational risks of $\mathrm{HBV}$ infection in patient admitted in RpMC\&H. A total number of 80 cases of hepatitis $B$ virus infected patients were selected from patients getting admission in indoor of Medicine and Gastroenterology department of Rangpur Medical College Hospital, Rangpur over the study period.

Among the 80 patients 58 (72\%) had the history of sexual exposure due to unprotected sex with HBsAg positive wife or patients, $08(10 \%)$ had the history of transfusions of blood or blood product either unscreened or improper screened, $05(06 \%)$ due to contaminated instrument injury, 04 (05\%) had history of professional blood donation without proper precaution, $03(04 \%)$ had the history of infusion either IM or IV, $02(03 \%)$ had the history of various surgery. In African study sexual exposure was $39 \%$ and transfusion with infusion was $21 \%(10)$. Another study in Netherland sexual exposure including commercial sex worker was 28\% where intravenous drug user was $41 \%{ }^{(11)}$. Which was not consistent in our study may be due to lack of knowledge and unprotected sex. Frequency of seropositivity among the study population also observed. A study in Yeamen it HBs Ag was $82 \%$ and Anti $\mathrm{HBc}$ was $62 \%(12)$ which was near about consistent with our study.

Adult vaccination has already had a substantial effect on the general level of hepatitis B immunity, (Table IV) this represents an ongoing public health challenge. At the same time, primary hepatitis $B$ vaccine failure and rapidly declining anti-HBs titres after vaccination may also affect the effectiveness. People in the youngest age group had a greater likelihood of being currently immune by vaccination against hepatitis B, compared with those aged over 50 having significantly less chance of being immune by vaccination. But males in the older age group likely became immune by exposure. The reason may be related to immune maturation and opportunities for exposure to HBV to generate antibodies, resulting in seroconversion. Booster doses of the hepatitis $B$ vaccine are regarded as unnecessary on the premise that a rapid anamnestic response will occur on challenge, and this policy is supported by the demonstration of antibody production after booster doses of the vaccine. Personal history of vaccination was determined by patient recall which affects the accuracy and impact of the study. We do not know vaccination age, Hep B genotype, vaccination doses, number of inoculation, and duration of HBV infection. However personal history of vaccination was associated with decreasing $\mathrm{HBsAg}$-positivity and increasing $\mathrm{HBsAb}$ positivity. The positive results increase our confidence in the use of the vaccine.

Regarding occupational relation (Fig 1) in this study shows businessman (36\%) are most vulnerable, this may be due to they are mostly go outside their residence for business purpose some time for a long time and are sexually exposed eventually. Then service holder (33\%), Student (09\%), daylabourer $(17 \%)$, farmer $(04 \%)$ and onwards in case of male but in female housewives (57\%) are most vulnerable in our country. This is due to male are more affected 
(table II) and transmitted to their partner by unprotected sex. In African study it service holder were the highest (44\%) in case of male and housewives $(67 \%)$ were in case of female ${ }^{(10)}$. Another study in yemen businessman (66\%) are mostly affected ${ }^{(12)}$. As our sample size was small, it may not represent the actual scenario. Moreover, in these tertiary level hospitals we get much information about risk factor of hepatitis B virus infected patient.

In conclusion, hepatitis $B$ infection remains in Bangladesh an important disease with substantial mortality and morbidity that primarily affects unvaccinated or inadequately vaccinated individuals. As Bangladesh, like most third world countries, has very limited resources, the continued occurrence of this preventable disease represents a drain on existing health care funds. This must be brought to the attention of institutions responsible for planning health care programmes.

\section{Acknowledgement}

We are grateful to Dr. Md.Golam Mostofa, Director of Rangpur Medical College Hospital for allowing us to collect the data of hepatitis B virus infected patients while we were working in medicine department of this hospital. We also like to thank all the Nurses caring for the hepatitis patients and to all the staffs working in this department for their cordial help during this study.

\section{References}

1. Lavanchy D. Hepatitis B virus epidemiology, disease burden, Treatment, and current and emerging prevention and control measure. J Viral Hepat. 2004; 11:97-107.
2. Qu JB, Zhang ZW, Shimbo S. Urban-rural comparison of HBV and HCV infection prevalence in eastern China. Biomed Environ Sci. 2000; 13:243-53.

3. Liaw YF. Management of patients with chronic hepatitis B. J Gastroenterol Hepatol. 2002; 17:406-8.

4. Edmunds WJ, Medley GF, Nokes DJ. The transmission dynamics and control of hepatitis B virus in The Gambia. Statistics in medicine.1996;30(15):2215-33.

5. Cheesbrough M. District laboratory practice in tropical countries, 3rd ed. Cambridge University press, UK. 2000;pp. 250-52.

6. Chang MH. Hepatitis B virus infection. Semin Fetal Neonatal Med. 2007; 12:160-67.

7. Alavian SM, Gooya MM, Hajarizadeh B, Esteghamati AR, Moeinza-deh AM, Haghazali M, et al. Mass Vaccination Campaign against Hepatitis $B$ in Adolescents in Iran: Estimating Coverage using Administrative Data. Hepat Mon.2009;9(3):189-95.

8. Alavian SM. Ministry of Health in Iran Is Serious about control-ling Hepatitis B. Hepat Mon. 2007;7(1):3-5.

9. Statistical Package for Social Sciences (SPSS) for Windows, Rel.11.0.1. Chicago: SPSS Inc; 2012.

10. Awole M, Gebre-Selassie G. Seroprevalence of HBsAg and its risk factors among pregnant women in Jimma, Southwest Ethiopia; Ethiop.J.Healh Dev. 2005;19(1)

11. Duynhoven Y T H P V, Laar M J W V, Schop W A, Ph H Rothbarth P H. Prevalence and risk factors for hepatitis $B$ virus infections among visitors to an STD clinic; Genitourin Med . 1997;73:488-492.

12. Shamahy H A. Prevalence of hepatitis b surface antigen and risk factors Of HBV infection in a sample of healthy mothers And their infants in sana'a, yemen; Annals of Saudi Medicine, Vol 20, Nos 5-6, 2000 